\title{
ОСОБЕННОСТИ ВЫБОРОВ В ЕВРОПЕЙСКИЙ ПАРЛАМЕНТ 2019 г. В ЧЕХИИ И СЛОВАКИИ
}

Аннотация. В статье обозначены особенности электорального процесса в Чехии и Словакии на выборах в Европейский парламент. Хотя в каждой из стран они имели свои отличительные черты, можно говорить и об общих тенденциях. Прежде всего, ввиду незначительной заинтересованности населения в общеевропейской проблематике, проявивщейся в низкой явке, партии сделали акиент на внутриполитических темах. Тем самым выборы стали для них промежуточным испытанием, в ходе которого наметились контуры изменений политического ландшафта на ближайшее будущее.

Ключевые слова: Чехия, Словакия, Центральная Европа, выборы в Европейский парламент, Европейский парламент, АНО, СМЕР - СД, Свобода и прямая демократия, Народная партия Наша Словакия.

Страны бывшего социалистического блока, несмотря на своё сильное желание «вернуться в Европу», которое было продекларировано в ходе «бархатных революций», на протяжении всех выборов в Европейский парламент (ЕП) не проявляли к ним должного энтузиазма, демонстрируя низкую явку. Это наглядно обнаруживается в сравнении с выборами в национальные органы власти (таб. 1).

Таблица 1

Участие граждан ЕС в национальных выборах и в выборах в Европейский парламент

\begin{tabular}{|c|c|c|}
\hline Страна & Bыборы в ЕП (2014), в \% & Парламентские выборы (2014-2019), в \% \\
\hline Болгария & 35,8 & 52,57 \\
\hline Словения & 24,6 & 52,64 \\
\hline Хорватия & 25,2 & 52,59 \\
\hline Румыния & 32,4 & 39,44 \\
\hline Венгрия & 29 & 70,22 \\
\hline Польша & 23,8 & 48,9 \\
\hline Чехия & 18,2 & 60,8 \\
\hline Словакия & 13,1 & 59,82 \\
\hline Литва & 47,4 & 50,55 \\
\hline Латвия & 30,2 & 54,6 \\
\hline Эстония & 36,5 & 63,6 \\
\hline
\end{tabular}

Источник: https://www.idea.int/data-tools/regional-comparison-view/521/40/Europe

Эксперты находят несколько объяснений подобной тенденции. Прежде всего, граждане этих стран не видят возможности оказывать влияние на принятие решений в европейских органах власти и поэтому не связывают с данными выборами последующего изменения своей жизни. Далее, они отмечают, что существует зависимость, которая коррелируется с уровнем одобрения членства их страны в Европейском союзе - чем оно ниже, тем меньше явка ${ }^{1}$. Та-

(C) Ведерников Михаил Владимирович - кандидат исторических наук, старший научный сотрудник Отдела исследований Центральной и Восточной Европы Института Европы РАН. Adpec: 125009, Россия, Москва, ул. Моховая, д. 11, стр. 3. E-mail: vishma@ mail.ru.

DOI: http://dx.doi.org/10.15211/vestnikieran320192329

${ }^{1}$ Nový M. Účast ve volbách do Evropského parlamentu 2014: Proč tak málo? Politics in Central Europe. 11. 2015.1 S. S. 40. 
ким образом, можно сделать заключение, что значительная часть населения этих стран пока что не прочувствовала свою принадлежность к Евросоюзу и важность участия в определении его судьбы. Показательным примером являются Чехия и Словакия, где уже на протяжении четырёх избирательных циклов фиксируются одни из самых низких показателей вовлечённости избирателей в общеевропейские выборы (таб. 2).

Таблица 2

Явка на выборах в Европейский парламент в Чехии и в Словакии

\begin{tabular}{|c|c|c|c|c|}
\hline Страна & ЕП 2019, \% & EП 2014,\% & $E \Pi 2009, \%$ & $E \Pi 2004, \%$ \\
\hline Словакия & 22,74 & 13,1 & 19,6 & 17 \\
\hline Чехия & 28,72 & 18,2 & 28,2 & 28,3 \\
\hline
\end{tabular}

Источник: kurzy.cz.

\section{Выборы в Чехии}

24-25 мая в Чешской Республике (ЧР) прошли выборы в ЕП, на которых была зафиксирована традиционно низкая явка, составившая $28,72 \%$. Впрочем, этот результат продемонстрировал повышение заинтересованности граждан страны к выборам подобного порядка ввиду $10 \%$-го роста по сравнению с волеизъявлением 5 -летней давности $(18,2 \%)^{1}$, что однако не помогло даже приблизиться к среднему общеевропейскому показателю (51\%). Победителем электорального цикла стало правящее движение АНО, которое получило 21,18\% (6 мест в ЕП), следом за ним расположилась Гражданская демократическая партия (ГДП) - 14,54\% (4 места); на третьем месте оказалась Чешская пиратская партия - 13,95\% (3 места); далее коалиция партий ТОР 09 и СТАН - 11,65\% (3 места); на пятом месте - партия «Свобода и прямая демократия» (СПД) - 9,14\% (2 места); на шестом - Христианско-демократический союз - Чехословацкая народная партия - 7,24\% (2 места); крайней партией, которой удалось преодолеть 5\%-ный рубеж, необходимый для попадания в ЕП, стала Коммунистическая партия Чехии и Моравии (КПЧМ) - 6,94\% (1 место $)^{2}$.

Главным итогом выборов стала убедительная победа АНО, возглавляемого нынешним премьер-министром Андреем Бабишем. В последние дни мая - начале июня 2019 г. он подвергся наступательной критике, как со стороны внутренней оппозиции, так и со стороны брюссельских органов из-за якобы злоупотреблений при использовании средств европейских фондов. Это не помешало движению А. Бабиша улучшить показатели по сравнению с прошлыми выборами на 5 пунктов (в 2014 г. - 16,13\%), что демонстрирует широкую поддержку населением его программы.

Прежде всего, в ней говорилось о необходимости проведения «существенной реформы ЕС», которая должна была привести к преобразованию этого объединения в «сильный союз с сильными государствами-членами». Для этого следовало чётко определить роль союзных институтов, настроить взаимодействие между Европейской комиссией и Европейским советом. ЧР стоило бороться за прямое воздействие на управление ЕС, для того чтобы он «действовал в меньшем объёме, но более эффективно». Важное место отводилось вопросам безопасности, где акцент делался на самостоятельности принятия решений в определении групп лиц, которым стоило предоставлять возможность на работу и на проживание в ЧР. В этой связи отмечалась важность защиты внешних границ шенгенского пространства, которая являлась «политической, символической и экономической ценностью». Следовало обеспечивать недоступность территории ЧР для нелегальной миграции и расширять применение политики возвра-

1 Czechia. 2014 European election results URL: https://www.election-results.eu/national-results/czechia/20142019/constitutive-session/

${ }^{2}$ Czechia. 2019 European election results. URL: https://www.election-results.eu/national-results/czechia/2019-2024/ Научно-аналитический вестник ИЕ РАН, 2019, №3 
щения незаконно находящихся в ЕС мигрантов. Существенное внимание уделялось борьбе за равную конкуренцию чешских фирм на общеевропейском рынке без избыточной бюрократии; недопустимости двойных стандартов при продовольственном обеспечении центральноевропейских стран. Вопрос перехода на евро в программе АНО был обозначен как неприоритетный, поскольку еврозона требовала изменений (при этом ЧР хотела принимать участие в обсуждении её реформ $)^{1}$.

Стоит отметить, что говорить о победившей АНО как о евроскептической политической силе не стоит, поскольку его представители не ставили под сомнение членство страны в Евросоюзе, которое является для них безальтернативным вариантом развития государственного развития ${ }^{2}$. Их восприятие западным сообществом в подобном ключе проистекало из демонстрируемого ими критичного отношения к институтам ЕС, заявлениях о необходимости учёта национальных предпочтений, сохранении национального суверенитета и предоставлении бо́льших возможностей для национальных органов власти. Таким образом, их стоит обозначать еврореформистами - политическими силами, предлагающими конструктивные варианты изменения устройства европейского интеграционного объединения.

На фоне усиления позиций АНО его коалиционные партнёры показали обратную тенденцию - потерю избирательной поддержки. Так, Чешская социал-демократическая партия (ЧСДП) продемонстрировала падение на 8 пунктов (с 14,17 до 3,95\%), что не позволило ей провести ни одного депутата в ЕП; КПЧМ также показала схожую динамику (с 10,98 до $6,94 \%)$, но ей удалось «удержаться на плаву». Объяснение подобной тенденции, как отмечают эксперты, заключается в том, что за последние годы АНО совершило существенный сдвиг влево $^{3}$, что привело к переходу близких к этим взглядам избирателей на его сторону и фактической ликвидации его союзников по правительству. Устранив партнёров, движение АНО оказалось в ситуации, когда усиление оппозиционных партий, которые получили в совокупности 47,4\% голосов и которые не были настроены на диалог с ним, обозначило неизбежную трансформацию чешского политического ландшафта в будущем. Её наступление могло произойти и раньше намеченного срока ввиду массовых демонстраций в ЧР ${ }^{4}$, лейтмотив которых сводился к немедленной отставке премьер-министра.

Несомненно, успешными оказались выборы для ГДП, которая ранее на местных выбоpax в ноябре 2018 г. показала усиление своих позиций. В сравнении с прошлыми общеевропейскими выборами было зафиксировано двойное увеличение поддержки (с 7,57 до 14,54\%). Её рост во многом объясняется переходом некоторой части электората от движения АНО к ГДП, которое оказалось втянуто в череду непрекращающихся скандалов. Данное обстоятельство оттолкнуло тех избирателей, которые ранее голосовали за программу, а не за политиче-

\footnotetext{
1 Program hnutí ANO pro volby do Evropského parlamentu. URL: https://www.anobudelip.cz/cs/makame/aktuality/ novinky/cesko-ochranime.-tvrde-a-nekompromisne-41915.shtml.

${ }^{2}$ В марте 2019 г. коалиционное правительство ЧР (АНО, Чешская социал-демократическая партия и Коммунистическая партия Чехии и Моравии) внесло на рассмотрение парламента закон о референдуме. Согласно нему, выдвинутый на всеобщее рассмотрение вопрос мог быть одобрен только при поддержке этой инициативы со стороны $1 \frac{4}{4}$ граждан страны (около 2 млн человек). На подобное голосование запрещалось выносить вопросы, касающиеся поправок в Конституцию, в налоговое законодательство, в международные договоры, в положения о членстве в ЕС и НАТО. См.: https://www.novinky.cz/domaci/500520-ano-cssd-a-pirati-se-shodli-na-zakonu-oreferendu.html?fbclid=IwAR1xjfeliiz2EzsvFxYm2CpXGQKH0Gook5om6O0YpR7bjscOYoJkXHTbk1I.

3 The 2019 European Election: how anti-Europeans plan to wreck Europe and what can be done to stop it. URL: https://www.ecfr.eu/specials/scorecard/the 2019 European election.

${ }_{4}^{4} 4$ июня 2019 г. на Вацлавской площади в Праге была устроена масштабная манифестация, в которой приняло участие около 120 тыс. человек. Главным требованием демонстрантов была немедленная отставка премьер-ми нистра Чехии А. Бабиша ввиду появившегося доклада брюссельских чиновников, в котором говорилось о необходимости возвращения выделенных ранее Чехии средств еврофондов. См.: https://www.lidovky.cz/domov/plnyvaclavak-proti-babisovi-centrum-prahy-opet-zaplnily-desetitisice-protestujicich.A190604_163749_ln_domov_rsa.
}

Научно-аналитический вестник ИЕ РАН, 2019, №3 
ский бренд и их идеологию. Это стало возможным во многом за счёт схожей еврореформистской программы, в которой не поддерживалась Общая европейская система распределения беженцев; подчёркивалась важность усиления внешних границ, взаимодействие со спецслужбами в предотвращении незаконной миграции, трансграничное сотрудничество. Вхождение в зону евро могло произойти только после её структурных реформ ${ }^{1}$.

Новичком в ЕП стала Чешская пиратская партия, которая впервые участвовала в подобных выборах. Её лозунги привлекли внимание молодого электората, проживающего в крупных городах и активно участвующего в политической жизни страны как в режиме «онлайн», так и в «офлайн». Благодаря глубокому проникновению в повседневную жизнь и массовому использованию социальных сетей этой группой населения возникла возможность достаточно быстрого и эффективного распространения «пиратских» идей на широкую аудиторию. Программа партии сводилась к необходимости установления общественного контроля над властью и введения личной ответственности политиков за совершённые ими действия, оказывающие влияние на жизнь граждан. Что касается политики в отношении Евросоюза, то отмечалась необходимость сохранения свобод (свободы передвижения, интернета, свободы от диктатуры и экстремизма), важность проведения «апгрейда» (сделать ЕС более транспарентным и наполненным смысла). Говорилось об обеспечении равных условий для достижения благосостояния граждан вне зависимости от страны их проживания². Тем самым продвигалась вовлечённость граждан в принятие решений на общеевропейском уровне; восприятие их предложений со стороны центральных органов Европейского союза.

Многообразие политического представительства Чехии в ЕП проявилось в том, что существенную поддержку со стороны избирателей получила крайне правая партия СПД во главе с Т. Окамурой, выступающая за прекращение членства в ЕС и НАТО. В сравнении с первой попыткой пробиться в ЕП, когда эта партия, тогда ещё под другим названием «Рассвет - прямая демократия», получила всего лишь 3,12\%, последние выборы показали троекратное увеличение поддержки (ещё больше в абсолютных показателях - 47 тыс. против 217 тыс. проголосовавших). Заметный рост популярности объясняется, прежде всего, миграционным кризисом, охватившим ЕС с 2015 г. В своём политическом арсенале СПД удалось аккумулировать набор опасностей, угрожавших чешскому государству, среди, которых были не только нелегальные мигранты, мусульмане, но и брюссельские бюрократы, посягавшие на часть национального суверенитета, предлагавшие введение обязательных квот для приёма беженцев. Помимо прочего, они подчёркивали, что европейская интеграция была напрямую направлена на создание сверхгосударства, в рамках которого происходило ослабление и последующая ликвидация национальных государств. В этой связи, они требовали проведение референдума о выходе ЧР из ЕС. Представители СПД полагали, что Евросоюз угрожал свободе и демократии; проводил политику, направленную на исламизацию континента. Также СПД выступала с позиций необходимости поддержки традиционных ценностей, среди которых наиболее важной является сохранение семьи, состоящей из мужчины и женщины.

\section{Выборы в Словакии}

25 мая в Словацкой республике прошли выборы в ЕП, на которых была зафиксирована самая низкая явка в ЕС, где проголосовало только 22,74\%. Впрочем, этот показатель был на 9\% выше результатов 5-летней давности. Их победителем стала коалиция недавно созданных

\footnotetext{
${ }^{1}$ Janebová P., Dostál V., Plenta P., Végh Z. EU Elections 2019: What do the Central European Political Parties stand for? URL: http://www.amo.cz/wp-content/uploads/2019/05/AMO_EU-Elections-2019.pdf.

${ }^{2}$ Volební program pro volby do EP 2019. URL: https://www.pirati.cz/program/europarlament2019.html.
} 
партий Сполу (Вместе) и «Прогрессивной Словакии»(20,11\%, 4 места в ЕП), последняя из которых на президентских выборах 2019 г. выдвинула кандидатуру победившей впоследствии Зюзанны Чапутовой ${ }^{1}$. На второе место переместился лидер предыдущих двух выборов в ЕП (2009 г. - 32\%, 2014 г. - 24,09\%) правящая партия СМЕР - СД, которая продемонстрировала тенденцию потери доверия избирателя и получила 15,72\% (2 места). Призовую тройку с результатом 12,07\% (2 места) замыкала националистическая, крайне правая партия Народная партия Наша Словакия (НПНС), которая впервые участвовала в подобных выборах. За ними следовали Христианско-демократическое движение (9,69\%, 1 место), партия «Свобода и солидарность» $(9,62 \%, 2$ места) и коалиция партий «Обычные люди и независимые личности» и $\operatorname{HOBA~}(5,25 \%, 1 \text { место })^{2}$.

Успехом проевропейской либеральной коалиции стало подтверждение намеченного ещё с марта 2018 г. тренда на усиление либеральных партий, находящихся в оппозиции правящему СМЕР - СД. Убийство тогда журналиста Я. Куциака и последовавшие за ним гражданские акции активизировали антиправительственное движение, которое привело к уходу в отставку премьера Р. Фицо, председателя СМЕР - СД³. Последовавшее в марте 2019 г. избрание на пост президента республики 3. Чапутовой обозначил чёткий курс на запрос граждан на новую власть. Будучи промежуточным этапом перед национальными парламентскими выборами майское волеизъявление обозначило падение популярности не только СМЕР - СД, но и его партнёров по коалиции, что свидетельствовало о неизбежных переменах в политической обстановке Словакии в ближайшем будущем и запросе определённой группы населения на более проевропейский курс. Так, в программе коалиции отмечалась её принадлежность к этим ценностям и стремление «строить и улучшать ЕС, а не подрывать и разрушать его». Делались обещания обеспечить в будущем европейский уровень зарплат и европейское качество жизни; акцентировалось внимание на проведение оценки состояния верховенства закона в государствах - членах Европейского союза для эффективной, прозрачной и независимой деятельности судебных органов $\mathrm{EC}^{4}$.

Впрочем, население голосовало не только за проевропейские лозунги коалиции, а против традиционных сил, смещение которых должно было вести к политическому обновлению, преодолению «порочных практик», поскольку СМЕР - СД не ставил под сомнение ориентацию на ЕС, которая была для него безальтернативна. В этой связи его программа, ориентированная на артикулирование достижений, которые были сделаны за время нахождения у власти (низкий уровень безработицы, низкий дефицит, социально ориентированные законы), рассматривалась как данность тем электоратом, который хотел большего и как можно скорее. Либеральные силы, появившиеся на политической сцене на волне политического кризиса, предлагали быстрые решения.

В то же самое время у словаков популярностью пользовалась партия НПНС, деятельность которой, по словам Г. Месежникова, «коренным образом противоречила всему тому, что формирует внутренний фундамент и внешние рамки общественного устройства страны» 5 . Ставя под сомнение внешнеполитическую ориентацию словацкого правительства и интеграцию в политические, экономические евро-атлантические структуры, НПНС всё же за послед-

\footnotetext{
${ }^{1}$ Ведерников М.В. Президентские выборы в Словакии 2019 года как кризис доверия власти. Научно-аналитический вестник Института Европы РАН, №2, 2019. С. 59.

${ }^{2}$ Slovakia. 2019 European election results. URL: https://www.election-results.eu/national-results/slovakia/2019-2024/

${ }^{3}$ Центральная Европа: политический портрет на фоне 100-летия». Под ред. Л.Н. Шишелиной, М.В. Ведерникова. М., 2018. С. 148-158.

${ }^{4}$ Náš plán. URL: https://stranaspolu.sk/program.

${ }^{5}$ Месежников Г. Подъём правого экстремизма - вызов либеральной демократии в Словакии. Мир перемен, №3, 2017. C. 131.
} 
ние годы с момента появления на политической сцене избавилась от реноме «правоэкстремистской фашизоидной партии» и переняла основные инструменты коммуникации с избирателями. Это в свою очередь привело к существенному росту электоральной поддержки и привлечению к себе сил, которые раньше избегали приобщения к партии с крайне радикальными взглядами. Лозунги о борьбе с «эскалацией цыганского террора» и «насильственной исламизацией» соседствовали с предложениями социального характера о необходимости поддержки молодёжи, обеспечении их рабочими местами и экономическими предложениями о поддержке сельского хозяйства и создании «здоровой экономики» ${ }^{1}$. Подобный «программный микс» лишал партию исключительно негативистского наполнения и вкладывал в неё содержательный смысл.

Призывая к проведению референдума о прекращении членства в Европейском союзе, лидер партии М. Котлеба параллельно говорил о необходимости присутствия представителей НПНС в Европарламенте для того, чтобы противостоять «либеральному безумству в Брюсселе», что можно было сделать, «объединившись с патриотами из Польши, Австрии и партией Виктора Орбана - ФИДЕС». Он считал, что чем больше противников ЕС было бы в ЕП тем активнее можно было противостоять «бессмысленным и опасным действиям евробюрократов».

$* \quad * \quad *$

Отсутствие заинтересованности в общеевропейских выборах у большинства населения Чехии и Словакии привело к тому, что политические силы акцентировали внимание на внутриполитической проблематике. Тем самым данные выборы стали дополнительной возможностью для партий заявить о себе и выяснить расстановку сил накануне местных выборов.

Что касается Чехии, всегда выделявшейся приверженностью демократическим ценностям, и Словакии, которая некоторое время после обретения независимости боролась между авторитаризмом и демократией, то выборы в ЕП подтвердили проевропейский курс этих стран и нежелание элит отклоняться от него. Между тем очевидным стало присутствие сил, которые ставили под сомнение членство в Европейском союзе и которые при этом имели значительную поддержку среди населения (9-10\%). Впрочем, они не оказывали никакого влияния на положение страны в ЕС и, вероятно, не будут способны изменить её положение, будучи представленными в ЕП. Наличие радикальных евроскептических сил на политической сцене Чехии и Словакии подтверждает их принадлежность к западному демократическому миру, где господствует плюрализм мнений и многообразие идейных предпочтений.

\section{Список литературы}

Ведерников М.В. Президентские выборы в Словакии 2019 года как кризис доверия власти. Научно-аналитический вестник Института Европы РАН, №2, 2019. С. 59-65.

Месежников Г. Подъём правого экстремизма - вызов либеральной демократии в Словакии. Мир перемен, 3, 2017. С. 116-135.

Центральная Европа: политический портрет на фоне 100-летия. Под ред. Л.Н. Шишелиной, М.В. Ведерникова. М., Институт Европы РАН, 2018.

\footnotetext{
1 Vol'by do Európskeho parlamentu 2019. URL: http://www.naseslovensko.net/kategoria/volby-do-europskehoparlamentu-2019/
}

Научно-аналитический вестник ИЕ РАН, 2019, №3 


\section{References}

Central'naya Evropa: politicheskij portret na fone 100-letiya. Pod red. L.N. Shishelinoj, M.V. Vedernikova. M., Institut Evropy RAN, 2018.

Czechia. 2019 European election results. URL: https://www.election-results.eu/nationalresults/czechia/2019-2024/

Mesezhnikov G. Pod"em pravogo ekstremizma - vyzov liberal'noj demokratii v Slovakii. Mir peremen, №3, 2017. S. 116-135.

Nový M. Účast ve volbách do Evropského parlamentu 2014: Proč tak málo? Politics in Central Europe. 11, 2015. 1S. S. 39-62.

Slovakia. 2019 European election results. URL: https://www.election-results.eu/nationalresults/slovakia/2019-2024/

Vedernikov M.V. Prezidentskie vybory v Slovakii 2019 goda kak krizis doveriya vlasti. Nauchno-analiticheskij vestnik Instituta Evropy RAN, №2, 2019. S. 59-65.

\section{Election in European Parliament 2019 in Czech Republic and Slovakia}

Author. Mikhail Vedernikov, Candidate of Sciences (History), Senior Research Associate of the Department of Central and Eastern European Studies, Institute of Europe, Russian Academy of Sciences. Address: 11-3, Mokhovaya str., Moscow, Russia, 125009. E-mail: vishma@mail.ru.

Abstract. The paper outlines the peculiarities of electoral process in the Czech Republic and Slovakia during elections to the European Parliament. Although both countries had their own distinctive features, it is worth to talk about the inherent features. First of all, due to low interest of Czechs and Slovaks in the European issues, which was manifested in a low turnout, the parties focused on domestic political issues. Thus, the elections became for them an intermediate test, during which changes in the political landscape were outlined.

Keywords: Czech Republic, Slovakia, Central Europe, elections to the European Parliament, the European Parliament, ANO, SMER - SD, the Freedom and Direct democracy, the People's Party Our Slovakia.

DOI: http://dx.doi.org/10.15211/vestnikieran320192329 